УДК 615.074

\title{
СОДЕРЖАНИЕ ОСНОВНЫХ ДЕЙСТВУЮЩИХ ВЕЩЕСТВ В КОРНЯХ ПРИРОДНОГО И ИНТРОДУЦИРОВАННОГО РАСТЕНИЯ SAPOSHNIKOVIA DIVARICATA (TURCZ.) SCHISCHK.
}

\author{
(C) Б.М. Урбагарова ${ }^{1}$ В.В. Тараскин ${ }^{2 * *}$, Т.В. Елисафенко ${ }^{3}$, Э.Э. Шульц ${ }^{4}$ Е.А. Королюк \\ Л.Д. Раднаева \\ ${ }^{1}$ Бурятский государственный университет имени Доржи Банзарова, \\ ул. Смолина, 24а, Улан-Удэ, 670000 (Россия) \\ ${ }^{2}$ Байкальский институт природопользования СО РАН, ул. Сахьяновой, 6, \\ Улан-Удэ, 670047 (Россия), e-mail: vvtaraskin@mail.ru \\ ${ }^{3}$ Центральный сибирский ботанический сад СО РАН, \\ ул. Золотодолинская, 101, Новосибирск, 630090 (Россия) \\ ${ }^{4}$ Новосибирский институт органической химии им. Н.Н. Ворожцова СО \\ РАН, пр. Академика Лаврентьева, 9, Новосибирск, 630090 (Россия)
}

Разработана методика количественного определения хромонов в корнях Saposhnikovia divaricata (Turcz.) Schischk. методом микроколоночной обращенно-фазовой ВЭЖХ с УФ-детектированием. Подобраны оптимальные параметры экстракции хромонов (двухкратная УЗ-экстракция длительностью 40 мин 50\% этиловым спиртом при соотношении сырье-экстрагент $1: 10)$. Валидационный анализ показал, что методика характеризуется удовлетворительными метрологическими показателями. Методика была применена для анализа дикорастущих, интродуцированных и коммерческих образцов сырья S. divaricata. В настоящей работе впервые в сапожниковии растопыренной корнях из природных популяций Бурятии, Забайкальского края, Монголии и в интродуцированном сырье методом ВЭЖХ-УФ определено количественное содержание основных действующих веществ: перв-О-глюкозилцимифугина $(0.13-5.22$ мг/г), цимифугина (0.01-1.82 мг/г) и 4'-О- $\beta$-D-глюкозил-5-О-метилвисамминола (0.98-3.25 мг/г). Суммарное содержание хромонов варьирует в зависимости от места сбора и фазы вегетации растений. Установлено содержание хромонов в двух образцах культивируемого сырья Saposhnikoviae divaricatae radices, собранных в первый год интродукции в разных природно-климатических условиях. Суммарное содержание хромонов в образце из Бурятии составило 4,45 мг/г, что в два раза больше по сравнению с образцом из Новосибирской области (2,03 мг/г).

Ключевые слова: Saposhnikovia divaricata (Turcz.) Schischk., перв-О-глюкозилцимифугин, 4'-O- $\beta$-D-глюкозил-5О-метилвиссаминол, цимифугин, ВЭЖХ.

Работа выполнена с использованием оборудования ЦКП БИП СО РАН (Улан-Удэ) в рамках гранта

Президента Российской Федерации для государственной поддержки молодых российских ученых №МК-501.2019.4. и при частичном финансировании в рамках госзадания БИП СО РАН.

\section{Введение}

Saposhnikovia Turcz. - эндемичный род Азии семейства Зонтичные (Umbelliferae), или Сельдерейные (Apiaceae). Единственный вид рода Saposhnikovia Turcz. - Saposhnikovia divaricata (Turcz.) Schischk. произрастает на территории Монголии, северной и северо-восточной территории Китая, Корейского полуострова

Урбагарова Баярма Мунхоевна - старший преподаватель кафедры фармации, e-mail: urbagarova.bayarma@mail.ru Тараскин Василий Владимирович - кандидат фармацевтических наук, старший научный сотрудник, e-mail: vvtaraskin@mail.ru и Российской Федерации. Ареал Saposhnikovia divaricata (Turcz.) Schischk. в России находится в южной области Восточной Сибири и юго-западной части Дальнего Востока, охватывая такие регионы,

Окончание на С. 144.

\footnotetext{
*Данная статья имеет электронный дополнительный материал (приложение), который доступен читателям на сайте журнала. DOI: 10.14258/jcprm.2021039152s

** Автор, с которым следует вести переписку.
} 
как Республика Бурятия, Амурская область, Забайкальский, Хабаровский и Приморский края $[1,2]$. Химический состав сапожниковии растопыренной корней представлен хромонами, кумаринами, полиацетиленовыми и азотсодержащими соединениями, фенолкарбоновыми кислотами, стероидами, жирными кислотами и полисахаридами. Основными действующими веществами считаются хромоны, из которых в наибольшем количестве накапливаются перв-О-глюкозилцимифугин, цимифугин и 4'-O- $\beta$-D-глюкозил-5-О-метилвиссаминол [3-7]. В недавнем исследовании китайскими учеными проведен сравнительный анализ жаропонижающей, анальгезирующей и противовоспалительной активностей трех доминирующих хромонов (цимифугин, перв-О-глюкозилцимифугин и 4'-O- $\beta$-D-глюкозил-5-О-метилвисамминол) и выявлено, что цимифугин обладает более выраженным, быстрым и продолжительным жаропонижающим эффектом в отличие от первО-глюкозилцимифугина. При исследовании анальгезирующей активности цимифугин также проявил более выраженный обезболивающий эффект в отличие от перв-О-глюкозилцимифугина и 4'-O- $\beta$-D-глюкозил-5О-метилвисамминола. Эти же вещества оказывают выраженный противовоспалительный эффект [8]. В практической медицине сапожниковии растопыренной корни применяются в виде настоек, экстрактов жидких и сухих, отваров, порошков при лихорадке, простуде. Однако это растение до сих пор не зарегистрировано в Государственном реестре лекарственных средств Российской Федерации, несмотря на то что оно произрастает в нескольких регионах страны и активно используется в практике частных клиник. Необходимо отметить, что ввиду высокой ценности данного растения для медицины, а также с возникновением острой проблемы рационального использования и сохранения вида вследствие массовых нерегулируемых заготовок корней $S$. divaricata населением Республики Бурятия, Забайкальского края для продажи, возросла актуальность интродукционных работ $[9,10]$ и исследований культивированного сырья. Данная работа имеет важное научное и практическое значение и необходима для стандартизации и разработки нормативной документации на лекарственное растительное сырье. Таким образом, целью настоящей работы является определение содержания цимифугина (далее C), перв-О-глюкозилцимифугина (далее GC) и 4'-O- $\beta$-D-глюкозил-5-О-метилвисамминола (далее MV) в корнях S. divaricata, собранных с ранее не изученных популяций на территории Республики Бурятия (далее - РБ), Забайкальского края (далее - Заб. край), а также в культивированном в условиях Новосибирской области и РБ сырье методом ВЭЖХ-УФ.

\section{Экспериментальная часть}

Растительное сырье. Объектами исследования послужили 17 образцов корней сапожниковии растопыренной флоры России (Республика Бурятия, Забайкальский край), Монголии (Хэнтэйский аймак), заготовленные в разные годы и разные онтогенетические стадии, а также сапожниковии растопыренной корни, приобретенные в аптечном учреждении г. Синин провинции Цинхай КНР, 2 коммерческих образца, реализуемых на территории РБ. Также сырье, интродуцированное на экспериментальном участке Центрального сибирского ботанического сада СО РАН (далее - ЦСБС СО РАН), в г. Новосибирске, расположенном на юго-востоке Западно-Сибирской равнины, в Северопредалтайской лесостепной провинции и на опытной площадке в Иволгинском районе РБ (образец любезно представлен д.фарм.н, проф. Т.А. Асеевой).

Общие экспериментальные условия. В качестве подвижной фазы в хроматографическом анализе использовали деионизированную воду, полученную на установке ICW-3000 (Millipore, Франция) и метанол Ultra Gradient HPLC Grade (J.T. Baker, Нидерланды). Содержание веществ рассчитывали по градуировочным графикам, построенным с применением коммерческих достоверных образцов GC (степень чистоты 98,94\%), MV (степень чистоты 99.19\%) производства ANPEL Laboratory Technologies (Shanghai) Inc. и рабочего стандартного образца С (степень чистоты 98\%), полученного в лаборатории медицинской химии в НИОХ им.

Елисафенко Татьяна Валерьевна - кандидат биологических наук, доцент, старший научный сотрудник, e-mail: tveli@ngs.ru

Шульи Эльвира Эдуардовна - доктор химических наук, профессор, заведующая лабораторией,

e-mail: schultz@nioch.nsc.ru

Королюк Елена Анатольевна - кандидат биологических наук, старший научный сотрудник,

e-mail: L_Koroljuk@ngs.ru

Раднаева Лариса Доржиевна - доктор химических наук, профессор, заведующая лабораторией, e-mail: radld@mail.ru
Н.Н. Ворожцова СО РАН. Результаты представлены в виде среднего значения из трех независимых определений. Для экстракции использовали спирт этиловый (96\%) производства «КонстантаФарм М» (Россия).

Определение содержания хромонов проводили с использованием высокоэффективного жидкостного хроматографа производства Agilent 1200 c диодно-матричным детектором (Agilent Technologies, США). Колонка Zorbax Eclipse XDB- 
C18 (4.6×150 мм, 5 мкм) (Agilent Technologies, США). В качестве подвижной фазы использовали смесь воды (элюент А) с метанолом (элюент Б), скорость потока 1.0 мл/мин при температуре $30{ }^{\circ} \mathrm{C}$. Градиентное элюирование осуществлялось по следующей схеме: 0-5 мин 60-45\% элюента А; 5-10 мин 45-40\% элюента А; 10-15 мин 40-0\% элюента А; 15-20 мин 0\% элюента А. На анализ вводили 5 мкл раствора, аналитическая длина волны - 300 нм. Внутрилабораторную воспроизводимость осуществляли на высокоэффективном жидкостном микроколоночном хроматографе Милихром А02 (ЗАО «ЭкоНова», Россия), оснащенном двухкомпонентным градиентным насосом, автосамплером, спектрофотометрическим детектором и термостатируемой стальной колонкой, заполненной сорбентом ProntoSIL 120-5-C18 (MetrohmAG, Швейцария; 1 мкм). В качестве подвижной фазы использовали смесь воды (элюент № 1) и метанола (элюент № 2); режим элюирования - градиентный 0-5 мин 60-45\% элюента № 1; 5-10 мин 45-40\% элюента № 1; 10-15 мин 40-0\% элюента № 1; 15-20 мин 0\% элюента № 1. Температура колонки - $35^{\circ} \mathrm{C}$, расход подвижной фазы - 100 мкл/мин, длина волны УФ-детектора - 300 нм, объем вводимой пробы - 5 мкл. Для экстракции хромонов из сырья использовали ультразвуковой диспергатор УЗДН-А (ООО «Укрросприбор», Украина) с рабочей частотой 22 кГц и орбитальный шейкер (IKA KS 130 Basic, Германия).

Валидационный анализ проводили согласно ОФС.1.1.0012.15 «Валидация аналитических методик» Государственной фармакопеи XIV издания [11].

\section{Обсуждение результатов}

Сапожниковии растопыренной корни (Saposhikoviae divaricatae radices) входят в Фармакопею Китайской Народной Республики, согласно которой, сырье стандартизуется по содержанию GC и MV, считающихся основными действующими веществами, их суммарное содержание должно быть не менее $0.24 \%$ [12]. Однако как было сказано ранее, С является не менее активным компонентом этого сырья, в связи с чем нами предложено проводить стандартизацию по трем хромонам. Для разработки методики количественного определения исследуемых веществ использовали сырье, заготовленное с территории Тарбагатайского района РБ в 2018 г. Первым этапом разработки методики количественного определения хромонов является подбор метода экстракции. Было получено 12 экстрактов четырьмя методами в трех параллелях: мацерация, ускоренная мацерация при нагревании, экстракция при комнатной температуре с помощью магнитной мешалки и ультразвуковая экстракция. Масса навески образцов составила 0.5 г (точная навеска), время экстракции для всех образцов, кроме полученных методом УЗ-экстракции (30 мин) - 90 мин. Количественное содержание хромонов определяли методом ВЭЖХ-УФ с использованием растворов стандартных образцов исследуемых веществ. Так, выявлено, что при использовании метода ускоренной мацерации наблюдается наибольший выход суммы хромонов, однако этот процесс является достаточно длительным, по сравнению с методом ультразвуковой экстракции. Выбор экстрагентов был основан на имеющихся сведениях о хорошей растворимости хромонов в спиртах. Наибольший выход GC, C и MV наблюдался при экстракции спиртом этиловым с концентрацией 50\% и метиловым спиртом с такой же концентрацией. В качестве экстрагента хромонов выбран спирт этиловый ввиду меньшей токсичности по сравнению с метанолом. Оптимальный выход трех хромонов наблюдался при соотношении сырье : экстрагент как $1: 10$. Целесообразно экстрагировать лекарственное растительное сырье двукратно, поскольку при третьем контакте наблюдался наименьший выход хромонов (табл. 1).

Таким образом, подобраны оптимальные условия экстракции и представлена методика определения количественного содержания хромонов в Saposhnikoviae divaricatae radices: около 2.5 г (точная навеска) измельченного сырья с размером частиц не более 2 мм помещают в плоскодонную колбу объемом 100 мл, прибавляют 25 мл спирта этилового 50\% и экстрагируют методом ультразвуковой экстракции при частоте 22 кГц при комнатной температуре в течение 40 минут. Извлечение фильтруют через фильтр «синяя лента» в мерную колбу вместимостью 50 мл. Остаток на фильтре переносят обратно в ту же колбу, прибавляют 25 мл этилового спирта 50\% и повторяют экстракцию в тех же условиях. Полученное извлечение снова отфильтровывают через тот же фильтр в ту же мерную колбу и доводят объем до метки этиловым спиртом той же концентрации. 
Таблица 1. Влияние технологических параметров на выход хромонов

\begin{tabular}{|c|c|c|c|c|c|c|c|c|c|}
\hline \multicolumn{2}{|c|}{ Параметр } & \multicolumn{3}{|c|}{$G C, \mathrm{Mг} / \Gamma$} & \multicolumn{3}{|c|}{$C, \mathrm{M \Gamma} / \Gamma$} & \multicolumn{2}{|c|}{$M V, \mathrm{M \Gamma} / \Gamma$} \\
\hline \multicolumn{10}{|c|}{ Метод экстракции } \\
\hline \multicolumn{2}{|l|}{ Мацерация } & \multicolumn{3}{|c|}{$1.05 \pm 0.09$} & \multicolumn{3}{|c|}{$0.32 \pm 0.02$} & \multicolumn{2}{|c|}{$0.29 \pm 0.14$} \\
\hline \multicolumn{2}{|c|}{ Ускоренная мацерация } & \multicolumn{3}{|c|}{$1.75 \pm 0.08$} & \multicolumn{3}{|c|}{$0.28 \pm 0.01$} & \multicolumn{2}{|c|}{$0.34 \pm 0.10$} \\
\hline \multicolumn{2}{|c|}{ С магнитной мешалкой } & \multicolumn{3}{|c|}{$0.81 \pm 0.05$} & \multicolumn{3}{|c|}{$0.42 \pm 0.004$} & \multicolumn{2}{|c|}{$0.98 \pm 0.04$} \\
\hline \multicolumn{2}{|l|}{ УЗ-экстракция } & \multicolumn{3}{|c|}{$1.42 \pm 0.07$} & \multicolumn{3}{|c|}{$0.33 \pm 0.02$} & \multicolumn{2}{|c|}{$0.36 \pm 0.04$} \\
\hline \multicolumn{10}{|c|}{ Экстрагент } \\
\hline \multicolumn{2}{|c|}{ Этиловый спирт 90\% } & \multicolumn{3}{|c|}{$1.42 \pm 0.07$} & \multicolumn{3}{|c|}{$0.33 \pm 0.02$} & $0.36 \pm$ & 0.02 \\
\hline Этиловый спир & $80 \%$ & & $1.44 \pm 0.04$ & & & $0.32 \pm 0.03$ & & $0.35 \pm$ & 0.01 \\
\hline Этиловый спирт & $70 \%$ & & $1.27 \pm 0.02$ & & & $0.37 \pm 0.02$ & & $0.33 \pm$ & 0.08 \\
\hline Этиловый спирл & $60 \%$ & & $1.35 \pm 0.05$ & & & $0.69 \pm 0.03$ & & $0.36 \pm$ & 0.01 \\
\hline Этиловый спи| & $\mathbf{5 0 \%}$ & & $1.38 \pm 0.03$ & & & $0.76 \pm 0.07$ & & $0.38 \pm$ & 0.01 \\
\hline Этиловый спирл & $40 \%$ & & $1.06 \pm 0.04$ & & & $0.63 \pm 0.09$ & & $0.32 \pm$ & 0.04 \\
\hline Этиловый спир & $30 \%$ & & $0.45 \pm 0.004$ & & & $0.85 \pm 0.06$ & & $0.29 \pm$ & 0.03 \\
\hline Метиловый спи & т $100 \%$ & & $1.32 \pm 0.07$ & & & $0.35 \pm 0.02$ & & $0.34 \pm$ & 0.05 \\
\hline Метиловый спи & т $80 \%$ & & $1.46 \pm 0.09$ & & & $0.34 \pm 0.02$ & & $0.39 \pm$ & 0.20 \\
\hline Метиловый спи & $70 \%$ & & $1.26 \pm 0.06$ & & & $0.42 \pm 0.03$ & & $0.34 \pm$ & 0.09 \\
\hline Метиловый спи & т $60 \%$ & & $1.11 \pm 0.06$ & & & $0.73 \pm 0.05$ & & $0.31 \pm$ & 0.03 \\
\hline Метиловый сп & 1рт $50 \%$ & & $1.26 \pm 0.08$ & & & $0.96 \pm 0.08$ & & $0.32 \pm$ & 0.06 \\
\hline Метиловый спи & $40 \%$ & & $1.19 \pm 0.03$ & & & $0.85 \pm 0.06$ & & $0.30 \pm$ & 0.09 \\
\hline & & & Соотно & шение сырь & е : экстраг & гент & & & \\
\hline $1: 150$ & & & $1.30 \pm 0.04$ & & & $0.61 \pm 0.09$ & & $0.35 \pm$ & 0.05 \\
\hline $1: 100$ & & & $1.38 \pm 0.03$ & & & $0.76 \pm 0.07$ & & $0.38 \pm$ & 0.01 \\
\hline $1: 75$ & & & $1.42 \pm 0.01$ & & & $0.79 \pm 0.04$ & & $0.45 \pm$ & 0.09 \\
\hline $1: 50$ & & & $1.55 \pm 0.09$ & & & $0.81 \pm 0.004$ & & $0.55 \pm$ & 0.07 \\
\hline $1: 25$ & & & $1.73 \pm 0.13$ & & & $0.79 \pm 0.04$ & & $0.71 \pm 0$ & .004 \\
\hline $1: 20$ & & & $2.03 \pm 0.01$ & & & $0.80 \pm 0.09$ & & $0.83 \pm$ & 0.09 \\
\hline $1: 15$ & & & $2.34 \pm 0.09$ & & & $0.83 \pm 0.12$ & & $0.97 \pm$ & 0.04 \\
\hline $1: 10$ & & & $2.56 \pm 0.07$ & & & $0.85 \pm 0.10$ & & $1.03 \pm$ & 0.08 \\
\hline $1: 5$ & & & $2.21 \pm 0.003$ & & & $0.83 \pm 0.09$ & & $0.95 \pm$ & 0.01 \\
\hline & & & Время & и кратност & ь экстракц & ции & & & \\
\hline & & & & & Экстракц & & & & \\
\hline Время мин & & $\mathrm{I}$ & & & II & & & III & \\
\hline Время, мин & $\begin{array}{c}G C, \\
\text { мГ/Г }\end{array}$ & $C, \mathrm{M \Gamma} / \Gamma$ & $\begin{array}{l}M V, \\
\text { мГ/Г }\end{array}$ & $\begin{array}{c}G C, \\
\mathrm{мг} / \Gamma\end{array}$ & $C, \mathrm{M} \Gamma / \Gamma$ & $\begin{array}{l}M V, \\
\text { мг/Г }\end{array}$ & $\begin{array}{c}G C, \\
\mathrm{мг} / \Gamma\end{array}$ & $C, \mathrm{M} \Gamma / \Gamma$ & $M V, \mathrm{M \Gamma} / \Gamma$ \\
\hline 20 & $2.77 \pm 0.10$ & $0.64 \pm 0.04$ & $0.84 \pm 0.08$ & $0.97 \pm 0.09$ & $0.11 \pm 0.01$ & $0.47 \pm 0.03$ & $0.38 \pm 0.07$ & $0.01 \pm 0.001$ & $0.16 \pm 0.01$ \\
\hline 30 & $2.80 \pm 0.07$ & $0.70 \pm 0.04$ & $0.94 \pm 0.08$ & $0.97 \pm 0.10$ & $0.25 \pm 0.01$ & $0.63 \pm 0.08$ & $0.09 \pm 0.10$ & $0.02 \pm 0.001$ & $0.10 \pm 0.01$ \\
\hline 40 & $2.85 \pm 0.08$ & $0.73 \pm 0.04$ & $0.98 \pm 0.05$ & $1.02 \pm 0.09$ & $0.20 \pm 0.01$ & $0.69 \pm 0.03$ & $0.20 \pm 0.03$ & $0.03 \pm 0.001$ & $0.11 \pm 0.03$ \\
\hline 50 & $2.84 \pm 0.06$ & $0.64 \pm 0.04$ & $0.94 \pm 0.02$ & $0.98 \pm 0.03$ & $0.19 \pm 0.01$ & $0.64 \pm 0.06$ & $0.18 \pm 0.08$ & $0.02 \pm 0.001$ & $0.09 \pm 0.002$ \\
\hline
\end{tabular}

При сравнительном анализе с данными Li W. и др., 2010 видно, что при подборе условий сверхкритической экстракции максимальный выход хромонов наблюдается при экстракции 50\% метанолом, что соответствует нашим данным [13]. По результатам U.M. Seo, 2016 разработана методика извлечения и определения многокомпонентного средства (пеуцеданол 7-O-b-D-глюкопиранозид, перв-О-глюкозилцимифугин, цимифугин, 4-O-b-D-глюкозил-5-О-метилвисамминол, бергаптен, втор-О-глюкозилгамаудол и императорин), при которой максимальный выход исследуемых компонентов наблюдается при экстракции 75\% этанолом при УЗ-экстракции. Однако в статье не даны результаты подбора условий экстракции и, возможно, при экстракции увеличивается суммарное содержание исследуемых компонентов, состоящих из кумаринов и хромонов [14].

Для анализа количественного содержания хромонов выбран метод высокоэффективной жидкостной хроматографии. Метод ВЭЖХ-УФ позволяет анализировать микроколичества, обеспечивает точность полученных результатов и экспрессность анализов. Так, по данным литературы, для количественного определения хромонов сапожниковии растопыренной преимущественно применяют метод высокоэффективной жидкостной хроматографии с диоидно-матричным детектором. В качестве элюента А преимущественно используют деионизованную воду, также есть пример использования в качестве элюента А - $10 \%$ раствор ацетонитрила для анализа совместного присутствия хромонов и кумаринов сапожниковии растопыренной, а в качестве элюента Б применяют метанол и ацетонитрил [12, 15-17]. Согласно требованиям Фармакопеи Китая, применяется изократический режим элюирования, но при хроматографировании данным методом 
пики получаются широкими, а время хроматографирования - более длительным. Для улучшения результатов предлагается градиентное элюирование, в результате чего сокращается время хроматографирования [17]. Температура колонки по разным данным составляла от 25 до $35{ }^{\circ} \mathrm{C}$, нами выбрана средняя температура $30{ }^{\circ} \mathrm{C}$ и аналитическая длина волны 300 нм, как в большинстве имеющихся работ. B статье U.M. Seо, 2016 указано, что для разделения семи маркерных соединений использование подвижной фазы вода-метанол является достаточной, как и в нашем случае [14]. Таким образом, на основании проведенного обзора нами выбраны условия анализа хромонов в Saposhnikoviae divaricatae radices и проведена оценка валидности аналитической методики по следующим параметрам: специфичность, линейность, правильность, сходимость и воспроизводимость.

Специфичность аналитического метода - это способность достоверно определять вещество в присутствии примесных соединений, продуктов деградации и вспомогательных веществ. В случае использовании хроматографического метода подтверждением специфичности служит показатель разрешения (Rs). Этот показатель характеризует способность системы разделить два компонента. Коэффициент разрешения между пиком GC и С составил 9.79, коэффициент разрешения между С и MV - 8.26, в то время как разрешение пика определяемого компонента с любым соседним пиком пробы должно быть более 1.5. Таким образом, примеси хромонов и растворителя для исследуемого образца не препятствуют их количественному определению.

Линейность устанавливается на основании результатов испытаний, которые пропорциональны концентрации анализируемого вещества в образце в пределах аналитической методики. Для определения данного параметра было приготовлено 6 растворов различной концентрации (1.50 мг/мл; 0.75 мг/мл; 0.50 мг/мл; 0.25 мг/мл; 0.15 мг/мл; 0.05 мг/мл) и построены калибровочные графики с расчетом коэффициента регрессии. Коэффициенты уравнения регрессии стандартных образцов GC, С и MV составили соответственно: 0.9937, 0.9910 и 0.9935. Данную методику можно считать линейной, т.к. коэффициент корреляции между рядом полученных значений не ниже 0.99 .

Правильность аналитического метода характеризует близость результатов испытаний, полученных данным методом, к истинному значению. Для определения правильности метода было приготовлено 9 растворов методом добавок в трех разных концентрациях в трех повторностях для каждого раствора стандартного образца и рассчитаны проценты восстановления. Для раствора GC в концентрации 0.4 мг/мл процент восстановления составил от 98.45 до 100.35\%, в концентрации 0.5 мг/мл - от 99.82 до $100.34 \%$, в концентрации 0.6 мг/мл - от 99.90 до 100.05\%; для С в концентрации 0,12 мг/мл процент восстановления составил от 99.67 до $100.33 \%$, в концентрации 0.15 мг/мл - от 99.47 до $100.90 \%$, в концентрации 0.18 мг/мл - от 99.50 до $100.41 \%$; для раствора MV в концентрации 0.4 мг/мл - от 99.88 до 100.13\%; в концентрации 0.5 мг/мл - от 98.90 до 100.80\%; в концентрации 0.6 мг/мл - от 99.87 до $100.18 \%$. Полученные результаты соответствуют требованиям, т.к. процент восстановления должен находиться в пределах от 98.0 до 102.0\%.

Сходимость (повторяемость) характеризует степень согласованности результатов измерений, полученных одним и тем же методом на идентичных объектах испытаний в одной и той же лаборатории одним и тем же оператором с использованием одного и того же оборудования в пределах короткого промежутка времени. Для проведения этого испытания хроматографировали по 6 параллельных образцов с одинаковой концентрацией и рассчитывали коэффициент вариации. Коэффициент вариации является отношением среднеквадратичного отклонения к среднеарифметическому значению результатов нескольких измерений. При анализе стандартных образцов GC и С коэффициенты вариации были одинаковыми и составили $0.00001 \%$, а для стандартного образца MV составил $0.005 \%$. Коэффициент вариации параллельных определений для шести измерений должен быть не более $2 \%$.

Внутрилабораторная воспроизводимость характеризует меру совпадения результатов измерений, полученных одним и тем же методом на идентичных образцах в одной лаборатории разными операторами с использованием различного оборудования с относительно длинным промежутком времени между измерениями. Анализы проводились на высокоэффективном жидкостном хроматографе Милихром А-02. Для определения данного показателя был рассчитан коэффициент вариации, который составил: для раствора GC $0.002 \%$, для C $-0.0006 \%$, для MV - 0.014\%. Коэффициент вариации внутрилабораторной воспроизводимости должен быть не более $2 \%$ для количественного определения основного компонента. Результаты оценки валидности и метрологическая характеристика предложенной методики представлены в таблицах 2 и 3 .

Таким образом, нами разработана методика количественного содержания хромонов в сапожниковии растопыренной корнях и проведена ее валидация. $\mathrm{C}$ использованием разработанной методики определено 
количественное содержание хромонов в сапожниковии растопыренной корнях Бурятии, Забайкальского края России, Монголии, коммерческом и в культивированном сырье (табл. 4).

Установлено, что содержание GC составляет от 0.13 до 5.22 мг/г; С - от 0.01 до 1.82 мг/г; MV - от 0.98 до 3.25 мг/г. Наибольшим содержанием GC характеризуется образец флоры Монголии. Высокое содержание С установлено в образце, собранном в окрестностях г. Кяхта в 2009 г., что, скорее всего, связано с процессами гидролиза при хранении (GC разрушается до C), а также данным хромоном богаты бурятский и китайский образцы (с. Тарбагатай Тарбагатайского района, ф. плодоношения; г. Сининь провинции Цинхай, аптечное сырье). Китайский образец сапожниковии растопыренной корней характеризуется большим содержанием не только C, но и MV. Образцы Забайкальского края отличаются одинаково высоким содержанием GC и MV. На примере Saposhnikoviae divaricatae radices, собранных в окрестностях с. Тарбагатай, видно, что в фазу плодоношения увеличивается содержание С почти на $88 \%$.

Таблица 2. Валидационные параметры разработанной методики

\begin{tabular}{|c|c|c|c|c|c|c|}
\hline \multicolumn{7}{|c|}{ Специфичность } \\
\hline & & & $G C$ & $C$ & $C$ & $M V$ \\
\hline \multicolumn{3}{|l|}{ Разрешение пика } & \multicolumn{2}{|l|}{9.79} & \multicolumn{2}{|r|}{8.26} \\
\hline \multicolumn{7}{|c|}{ Линейность } \\
\hline & & & $G C$ & & & $M V$ \\
\hline Коэффициент регрессии & & & 0.9998 & & & 0.9993 \\
\hline \multicolumn{7}{|c|}{ Правильность } \\
\hline \multirow{3}{*}{ Процент восстановления } & \multirow{3}{*}{$\mathrm{C}, \%$} & 80 & $98.45-100.35$ & 99 . & & $99.88-100.13$ \\
\hline & & 100 & $99.82-100.34$ & 99 . & & $98.90-100.80$ \\
\hline & & 120 & $99.90-100.05$ & 99. & & $99.87-100.18$ \\
\hline \multicolumn{7}{|c|}{ Сходимость } \\
\hline Среднеквадратичное отклонение & & & 0.00005 & & & 0.00002 \\
\hline Среднеарифметическое значение & & & 0.4999 & & & 0.4999 \\
\hline Коэффициент вариации & & & 0.00001 & & & 0.0050 \\
\hline \multicolumn{7}{|c|}{ Внутрилабораторная воспроизводимость } \\
\hline Среднеквадратичное отклонение & & & 0.0011 & & & 0.0069 \\
\hline Среднеарифметическое значение & & & 0.4999 & & & 0.5000 \\
\hline Коэффициент вариации & & & 0.0020 & & & 0.0140 \\
\hline
\end{tabular}

Таблица 3. Метрологическая характеристика методики количественного определения хромонов в Saposhnikoviae divaricatae radices

\begin{tabular}{c|c|c|c|c|c|c|c|c|c|cc}
\hline Компонент & $\mathrm{n}$ & $f$ & $\overline{\mathrm{x}}, \mathrm{мг} / \Gamma$ & $S^{2}$ & $S$ & $S_{\bar{x}}$ & $P, \%$ & $t(P, f)$ & $\Delta \mathrm{x}$ & $\bar{\varepsilon}, \%$ \\
\hline $\mathrm{GC}$ & & & 0.4999 & 0.00005 & 0.0069 & 0.00282 & & & 0.0072 & 1.45 \\
$\mathrm{C}$ & \multirow{2}{*}{5} & 0.1500 & 0.00001 & 0.0030 & 0.00129 & 95 & 2.57 & 0.0033 & 2.20 \\
$\mathrm{MV}$ & & & 0.4999 & 0.00009 & 0.0095 & 0.00387 & & & 0.0099 & 1.99 \\
\hline
\end{tabular}

Таблица 4. Количественное содержание (мг/г) хромонов в сапожниковии растопыренной корнях разных мест произрастания

\begin{tabular}{c|l|c|c|c}
\hline$№$ п/п & \multicolumn{1}{|c|}{ Место сбора / год сбора / фаза развития } & $G C$ & $C$ & $M V$ \\
\hline 1 & Кяхтинский район РБ РФ / 2009 / фаза цветения & $0.13 \pm 0.005$ & $1.82 \pm 0.06$ & $1.52 \pm 0.05$ \\
2 & Мухоршибирский район РБ РФ / 2015 / фаза цветения & $3.53 \pm 0.16$ & $0.55 \pm 0.02$ & $0.98 \pm 0.04$ \\
3 & Тарбагатайский район РБ РФ / 2016 / фаза плодоношения & $2.95 \pm 0.23$ & $0.14 \pm 0.02$ & $1.42 \pm 0.10$ \\
4 & Тарбагатайский район РБ РФ / 2017 / фаза плодоношения & $3.97 \pm 0.06$ & $0.10 \pm 0.004$ & $1.73 \pm 0.04$ \\
5 & Тарбагатайский район РБ РФ / 2018 / фаза плодоношения & $4.07 \pm 0.31$ & $1.08 \pm 0.01$ & $1.91 \pm 0.16$ \\
6 & Тарбагатайский район РБ РФ / 2018 / фаза вегетации & $4.63 \pm 0.18$ & $0.14 \pm 0.006$ & $1.81 \pm 0.08$ \\
7 & Тарбагатайский район РБ РФ / 2019 / фаза плодоношения & $6.32 \pm 0.15$ & $0.20 \pm 0.02$ & $3.28 \pm 0.09$ \\
8 & Иволгинский район РБ РФ / 2018 / фаза вегетации & $3.75 \pm 0.14$ & $0.18 \pm 0.06$ & $1.70 \pm 0.06$ \\
9 & Джидинский район РБ РФ / 2019/ фаза цветения & $4.77 \pm 0.20$ & $0.30 \pm 0.01$ & $1.77 \pm 0.04$ \\
10 & Агинский район Заб. край РФ / 2014 / фаза вегетации & $4.94 \pm 0.24$ & $0.23 \pm 0.01$ & $2.74 \pm 0.12$ \\
11 & Кыренский район Заб. край РФ / 2014 / фаза вегетации & $4.95 \pm 0.19$ & $0.24 \pm 0.01$ & $2.14 \pm 0.08$ \\
12 & Хэнтэйский аймак Монголии / 2013 / фаза плодоношения & $5.22 \pm 0.18$ & $0.29 \pm 0.01$ & $2.90 \pm 0.09$ \\
13 & Хэнтэйский аймак Монголии / 2015 / фаза плодоношения & $3.80 \pm 0.09$ & $0.69 \pm 0.02$ & $1.86 \pm 0.05$ \\
14 & ЦСБС СО РАН, Новосибирская область, РФ / 2018 / фаза вегетации & $0.83 \pm 0.03$ & $0.01 \pm 0.004$ & $1.19 \pm 0.05$ \\
15 & Иволгинский район РБ, РФ / 2019 / фаза вегетации & $2.36 \pm 0.11$ & $0.15 \pm 0.06$ & $1.94 \pm 0.06$ \\
16 & Агинский район ЗК, РФ / 2019 /* & $2.84 \pm 0.09$ & $0.37 \pm 0.04$ & $1.44 \pm 0.09$ \\
17 & Аптечное сырье, г. Синин, провинция Цинхай, Китай / 2015/* & $2.70 \pm 0.12$ & $1.06 \pm 0.04$ & $3.25 \pm 0.14$ \\
\hline
\end{tabular}

* аптечное и коммерческое сырье соответствовало разработанным нами ранее показателям доброкачественности [18]. 
Ценными являются результаты определения хромонов в двух образцах культивируемого сырья Saposhnikoviae divaricatae radices, собранных в первый год интродукции в разных природно-климатических условиях (Новосибирская область и РБ). На данном этапе можно отметить, что сырье из РБ характеризуется большим накоплением GC и MV, по сравнению с образцом из Новосибирской области. Известно, что содержание хромонов значительно повышается при неблагоприятных условиях, поскольку хромоны вместе с пероксидазой становятся основными веществами, устраняющими активные формы кислорода, как это показано для С и других хромонов в работах $[19,20]$.

\section{Bыводы}

Сапожниковия растопыренная - Saposhnikovia divaricata (Turcz.) Schischk. - является одним из наиболее известных видов, используемых в традиционной и народной медицине азиатских стран. Широкий спектр фармакологической активности обусловлен наличием полифенольных соединений, основными из которых являются хромоны. Большинство нормативных документов стран Востока рекомендуют проведение количественной стандартизации данного вида растительного сырья по содержанию хромонов - GC и $\mathrm{MV}$, однако ввиду высокой активности C нами предлагается стандартизовать сырье по содержанию 3 хромонов - C, GC и MV. Часто применяемым методом количественного анализа хромонов в сапожниковии растопыренной корнях является ВЭЖХ. Разработанная нами методика количественного анализа хромонов методом ВЭЖХ-УФ отличается экспрессностью и удовлетворительными метрологическими параметрами и предлагает оптимальные условия хроматографического разделения. Анализ образцов подтвердил перспективность применения данной методики в фармацевтической практике.

\section{Список литературы}

1. Пименов М.Г., Остроумова Т.А. Зонтичные (Umbilliferae) России. М., 2012. 477 с.

2. Растительные ресурсы России. Дикорастущие цветковые растения, их компонентный состав и биологическая активность. Т. 3. Семейства Fabaceae-Арiaceae / отв. ред. А.Л. Буданцев. СПб.; М., 2010. 256 с.

3. Yang M., Wang C., Wang W., Xu J., Wang J. Zhang C., Li M. Saposhnikovia divaricata - An Ethnopharmacological, Phytochemical and Pharmacological Review // Chin. J. Integr. Med. 2020. Vol. 26. Pp. 873-880. DOI: 10.1007/s11655-020-3091-x.

4. Urbagarova B.M., Shults E.E., Taraskin V.V., Radnaeva L.D., Petrova T.N., Rybalova T.V., Frolova T.S., Pokrovskii A.G., Ganbaatar J. Chromones and coumarins from Saposhnikovia divaricata (Turcz.) Schischk. Growing in Buryatia and Mongolia and their cytotoxicity // J. of Ethnopharmacology. 2020. Vol. 261. 112517. DOI: 10.1016/j.jep.2019.112517.

5. Kreiner J., Pang E., Lenon G.B., Yang A.W.H. Saposhnikoviae divaricata: a phytochemical, pharmacological, and pharmacokinetic review // Chin. J. of Nat. Med. 2017. Vol. 15. N4. Pp. 255-264. DOI: 10.1016/S1875-5364(17)30042-0.

6. Урбагарова Б.М., Тараскин В.В. Определение суммарного содержания флавоноидов, дубильных веществ и полисахаридов в Saposhnikoviae divaricatae radices // Вопросы биологической, медицинской и фармацевтической химии. 2019. Т. 22. №10. С. 25-29.

7. Urbagarova B.M., Taraskin V.V., Shults E.E., Radnaeva L.D., Anenkhonov O.A., Ganbaatar Zh., Boldanova N.B. Biologically Active Compounds from the Lipid Fraction of Saposhnikovia divaricata // Chemistry of Natural Compounds. 2017. Vol. 53. N1. Pp. 138-140.

8. Yang J.-M., Jiang H., Dai H.-L., Wang Z.-W., Jia G.-Zh., Meng X.-C. Feeble antipyretic, analgesic, and anti-inflammatory activities were found with regular dose 4'-O- $\beta$-D-glucosyl-5-O-methylvisamminol, one of the conventional marker compounds for quality evaluation of Radix Saposhnikoviae // Pharmacognosy Magazine. 2017. Vol. 13. N49. Pp. 168-174. DOI: 10.4103/0973-1296.197637.

9. Урбагарова Б.М., Тараскин В.В., Раднаева Л.Д. Saposhnikovia divaricata (Turcz.) Schischkin: Химический состав, перспективы использования и проблемы сохранения // Вестник Бурятского государственного университета. Биология. География. 2016. Т. 2. №3. С. 100-104.

10. Корсун О.В. Трансграничный спрос создаёт угрозу растениям Даурской степи // Степной бюллетень. 20182019. №51-52. С. 49-51.

11. Государственная фармакопея Российской Федерации: в 4 томах, XIV изд. M., 2018. URL: http://femb.ru/femb/pharmacopea.php.

12. Committee for the Pharmacopoeia of PR China. Pharmacopoeia of PR China (Part I). Beijing: People's Medical Publishing House, 2015. 150 p.

13. Li W., Wang Z., Chen L., Zhang J., Han L., Hou J., Zheng Y. Pressurized liquid extraction followed by LC - ESI/MS for analysis of four chromones in Radix Saposhnikoviae // J. Sep. Sci. 2010. Vol. 33. Pp. 2881- 2887. DOI: $10.1002 /$ jssc. 201000336 . 
14. Seo U.M., Zhao B.T., Kim Y.H., Kang J.S., Son J.K., Woo M.H. Simultaneous analysis of seven marker compounds from Saposhnikoviae Radix, Glehniae Radix and Peucedani Japonici Radix by HPLC/PDA. // Arch. Pharm. Res. 2016. Vol. 39. Pp. 695-704. DOI: 10.1007/s12272-016-0740-x.

15. Yu X., Niu Y., Zheng J., Liu H., Jiang G., Chen J., Hong M. Radix Saposhnikovia extract suppresses mouse allergic contact dermatitis by regulating dendritic-cell-activated Th1 cells // Phytomedicine. 2015. Vol. 22. N13. Pp. 11501158. DOI: 10.1016/j.phymed.2015.09.002.

16. Kim M.K., Yang D-H., Jung M., Jung E.H., Eom H.Y., Suh J.H., Min J., Kim U., Min H., Kim J., Han S.B. Simultaneous determination of chromones and coumarins in Radix Saposhnikoviae by high performance liquid chromatography with diode array and tandem mass detectors // J. of Chromatography A. 2011. Vol. 1218. Pp. 6319-6330. DOI: 10.1016/j.chroma.2011.06.103.

17. Scherubl R., Manns D., Heilmann J., Franz G. Comparison of HPLC Versus HPTLC-Densitometry for the Quantification of chromone glycosides in Saposhnikoviae divaricatae radix // Chromatographia. 2013. Vol. 76. Pp. 1537-1543. DOI: $10.1007 / \mathrm{s} 10337-013-2518-3$

18. Урбагарова Б.М. Фармакогностическое исследование сапожниковии растопыренной (Saposhnikovia divaricata (Turcz.) Schischkin) корней и разработка на их основе экстракта сухого: дис. ... канд. фарм. наук. Улан-Удэ, 2019. $162 \mathrm{c}$.

19. Jian H., Yang J.M., Jia G.Z., Dai H.L., Cao L., Meng X.C. Physical and Ecological Impacts of Chromones of Fresh Root of Saposhnikovia divaricata Exposure to High Temperature // Russian J. of Plant Physiology. 2018. Vol. 65. N5. Pp. 680-687. DOI: 10.1134/S1021443718050084.

20. Zeng L.J., Sun Q.S., Jia L.Y. Content determination of four components from different habitats and different parts of Saposhnikoviae divaricata (Turcz.) Schischk. by RP-HPLC // J. Shenyang Pharm. Univ. 2009. Vol. 26. N2. Pp. 127-130.

Поступила в редакиию 19 января 2021 г.

После переработки 17 февраля 2021 г.

Принята к публикациии 27 ревраля 2021 г.

Для цитирования: Урбагарова Б.М., Тараскин В.В., Елисафенко Т.В., Шульц Э.Э., Королюк Е.А., Раднаева Л.Д. Содержание основных действующих веществ в корнях природного и интродуцированного растения Saposhnikovia divaricata (Turcz.) Schischk. // Химия растительного сырья. 2021. №3. С. 143-151. DOI: $10.14258 /$ jcprm.2021039152.

Urbagarova B.M. ${ }^{1}$, Taraskin V.V..$^{2}$, Elisafenko T.V. ${ }^{3}$, Shults E.E. ${ }^{4}$, Korolyuk E.A. ${ }^{3}$, Radnaeva L.D. ${ }^{2}$ QUANTITATIVE CONTENT OF THE MAIN ACTIVE SUBSTANCES IN THE ROOTS OF THE NATURAL AND INTRODUCED PLANT SAPOSHNIKOVIA DIVARICATE (TURCZ.) SCHISCHK.

${ }^{1}$ Buryat State University named after Dorzhi Banzarov, ul. Smolina, 24a, Ulan-Ude, 670000 (Russia)

2 Baikal Institute of Nature Management SB RAS, ul. Sakhyanova, 6, Ulan-Ude, 670047 (Russia),

e-mail:vvtaraskin@mail.ru

${ }^{3}$ Central Siberian Botanical Garden SB RAS, ul. Zolotodolinskaya, 101, Novosibirsk, 630090 (Russia)

${ }^{4}$ Novosibirsk Institute of Organic Chemistry. N.N. Vorozhtsov SB RAS, pr. Acad. Lavrent'eva, 9, Novosibirsk, 630090 (Russia)

A HPLC-UV method was developed for the quantitative analysis of chromones in the roots of Saposhnikovia divaricata (Turcz.) Schischk. The optimal parameters of chromones extraction (two-fold ultrasonic extraction with a duration of 40 min with $50 \%$ ethyl alcohol at a raw material-extractant ratio of 1:10) were selected. The validation analysis showed that the proposed method is characterized by satisfactory metrological parameters. The method was used for the analysis of raw materials of wild, introduced and commercial samples of $S$. divaricata. In this work, for the first time in the roots of $S$. divaricata from natural populations of Buryatia, Trans-Baikal Territory, Mongolia and in the introduced samples, the HPLC-UV method was used to determine the quantitative content of the main active substances: prim- $O$-glucosylcimifugine $(0.13-5.22 \mathrm{mg} / \mathrm{g})$, cimifugine $(0.01-1.82 \mathrm{mg} / \mathrm{g})$ and 4'-O- $\beta$-D-glucosyl-5-O-methylvisamminol $(0.98-3.25 \mathrm{mg} / \mathrm{g})$. The total content of chromones varies depending on the place of collection and the phase of vegetation. The content of chromones in two samples of roots from introduced $S$. divaricatae, collected in the first year of introduction in different climatic conditions, was established.

Keywords: Saposhnikovia divaricata (Turcz.) Schischk., prim-O-glucosylcimifugine, 4'-O- $\beta$-D-glucosyl-5-O-methylvisamminol, cimifugine, HPLC.

\footnotetext{
${ }^{*}$ Corresponding author.
} 


\section{References}

1. Pimenov M.G., Ostroumova T.A. Zontichnyye (Umbelliferae) Rossii. [Umbelliferae of Russia]. Moscow, 2012,477 p. (in Russ.).

2. Rastitel'nyye resursy Rossii. Dikorastushchiye tsvetkovyye rasteniya, ikh komponentnyy sostav i biologicheskaya aktivnost'. T. 3. Semeystva Fabaceae-Apiaceae [Plant resources of Russia. Wild flowering plants, their component composition and biological activity. Vol. 3. Family Fabaceae-Apiaceae], ed. A.L. Budantsev. St.-Petersburg, Moscow, 2010, 256 p. (in Russ.).

3. Yang M., Wang C., Wang W., Xu J., Wang J. Zhang C., Li M. Chin. J. Integr. Med., 2020, vol. 26, pp. 873-880. DOI: 10.1007/s11655-020-3091-x.

4. Urbagarova B.M., Shults E.E., Taraskin V.V., Radnaeva L.D., Petrova T.N., Rybalova T.V., Frolova T.S., Pokrovskii A.G., Ganbaatar J. J. of Ethnopharmacology, 2020, vol. 261, 112517. DOI: 10.1016/j.jep.2019.112517.

5. Kreiner J., Pang E., Lenon G.B., Yang A.W.H. Chin. J. of Nat. Med., 2017, vol. 15, no. 4, pp. 255-264. DOI: 10.1016/S1875-5364(17)30042-0.

6. Urbagarova B.M., Taraskin V.V. Voprosy biologicheskoy, meditsinskoy i farmatsevticheskoy khimii, 2019, vol. 22, no. 10, pp. 25-29. (in Russ.).

7. Urbagarova B.M., Taraskin V.V., Shults E.E., Radnaeva L.D., Anenkhonov O.A., Ganbaatar Zh., Boldanova N.B. Chemistry of Natural Compounds, 2017, vol. 53, no. 1, pp. 138-140.

8. Yang J.-M., Jiang H., Dai H.-L., Wang Z.-W., Jia G.-Zh., Meng X.-C. Pharmacognosy Magazine, 2017, vol. 13, no. 49, pp. 168-174. DOI: 10.4103/0973-1296.197637.

9. Urbagarova B.M., Taraskin V.V., Radnayeva L.D. Vestnik Buryatskogo gosudarstvennogo universiteta. Biologiya. Geografiya, 2016, vol. 2, no. 3, pp. 100-104. (in Russ.).

10. Korsun O.V. Stepnoy byulleten', 2018-2019, no. 51-52, pp. 49-51. (in Russ.).

11. Gosudarstvennaya farmakopeya Rossiyskoy Federatsii: v 4 tomakh, XIV izd. [State Pharmacopoeia of the Russian Federation: in 4 volumes, XIV ed.]. Moscow, 2018. URL: http://femb.ru/femb/pharmacopea.php. (in Russ.).

12. Committee for the Pharmacopoeia of PR China. Pharmacopoeia of PR China (Part I). Beijing: People's Medical Publishing House, 2015, 150 p.

13. Li W., Wang Z., Chen L., Zhang J., Han L., Hou J., Zheng Y. J. Sep. Sci., 2010, vol. 33, pp. 2881- 2887. DOI: $10.1002 /$ jssc. 201000336 .

14. Seo U.M., Zhao B.T., Kim Y.H., Kang J.S., Son J.K., Woo M.H. Arch. Pharm. Res., 2016, vol. 39, pp. 695-704. DOI: 10.1007/s12272-016-0740-x.

15. Yu X., Niu Y., Zheng J., Liu H., Jiang G., Chen J., Hong M. Phytomedicine, 2015, vol. 22, no. 13, pp. 1150-1158. DOI: 10.1016/j.phymed.2015.09.002.

16. Kim M.K., Yang D-H., Jung M., Jung E.H., Eom H.Y., Suh J.H., Min J., Kim U., Min H., Kim J., Han S.B. J. of Chromatography A, 2011, vol. 1218, pp. 6319-6330. DOI: 10.1016/j.chroma.2011.06.103.

17. Scherubl R., Manns D., Heilmann J., Franz G. Chromatographia, 2013, vol. 76, pp. 1537-1543. DOI: 10.1007/s10337013-2518-3

18. Urbagarova B.M. Farmakognosticheskoye issledovaniye sapozhnikovii rastopyrennoy (Saposhnikovia divaricata (Turcz.) Schischkin) korney i razrabotka na ikh osnove ekstrakta sukhogo: dis. ... kand. farm. nauk. [Pharmacognostic study of shoemaker's spreading (Saposhnikovia divaricata (Turcz.) Schischkin) roots and development of dry extract on their basis: dis. ... Cand. farm. sciences]. Ulan-Ude, 2019, 162 p. (in Russ.).

19. Jian H., Yang J.M., Jia G.Z., Dai H.L., Cao L., Meng X.C. Russian J. of Plant Physiology, 2018, vol. 65, no. 5, pp. 680687. DOI: $10.1134 / \mathrm{S} 1021443718050084$.

20. Zeng L.J., Sun Q.S., Jia L.Y. J. Shenyang Pharm. Univ., 2009, vol. 26, no. 2, pp. 127-130.

Received January 19, 2021

Revised February 17, 2021

Accepted February 27, 2021

For citing: Urbagarova B.M., Taraskin V.V., Elisafenko T.V., Shults E.E., Korolyuk E.A., Radnaeva L.D. Khimiya Rastitel'nogo Syr'ya, 2021, no. 3, pp. 143-151. (in Russ.). DOI: 10.14258/jcprm.2021039152. 
